\title{
Índice de propensão à desertificação no estado do Ceará
}

\author{
Rogério Barbosa Soares" \\ Kilmer Coelho Campos***
}

\section{Resumo}

O presente estudo objetivou elaborar um índice de propensão à desertificação (IPD) para municípios do estado do Ceará, utilizando-se de técnicas de análise multivariada. Os dados de natureza secundária foram coletados do Instituto de Pesquisa e Estratégia Econômica do Ceará (Ipece, 2009), abordando variáveis referentes a fatores naturais e antrópicos. Foram selecionados 10 municípios vizinhos de alto risco de desertificação no Ceará. Os resultados mostraram que os indicadores que mais influenciaram quanto à propensão à desertificação foram os fatores climáticos e os fatores antrópicos causados pelo homem, tais como a expansão da fronteira agrícola, a superexploração dos minifúndios e o aumento do rebanho de ovinos e caprinos, os quais provocam um aumento da compactação do solo pela forte pressão sobre o pasto existente, que, ao longo dos anos, provoca a desertificação.

Palavras-chave: Fatores naturais e antrópicos. Análise fatorial. Ceará.

* Mestre em Economia Rural pela Universidade Federal do Ceará (UFC) e especialista em Desenvolvimento Econômico pela Universidade Federal do Ceará (UFC). E-mail: rogeriosoares77@gmail.com

** Professor Adjunto do Departamento de Economia Agrícola da Universidade Federal do Ceará (UFC) Campus Pici e Doutor em Economia Aplicada pela Universidade Federal de Viçosa (UFV). Rua Antônio Augusto, 3030, apto. 508, B. Aldeota, 60.110-371, Fortaleza - CE. Fone: (85) 8619.0490 / (85) 3366.9716. E-mail: kilmer@ufc.br 


\section{Introdução}

De acordo com a Convenção das Nações Unidas de Combate à Desertificação e Mitigação dos Efeitos da Seca (UNCCD), a desertificação é a degradação de terras situadas em zonas de diferentes níveis de aridez. A desertificação é um processo que lentamente destrói a base de recursos naturais de determinada área, e que leva à inviabilidade parcial ou definitiva de convivência de uma comunidade, ensejando a má qualidade de vida, a impossibilidade de obtenção de renda digna, estimulando a migração de sociedades inteiras.

O Nordeste brasileiro, considerado como uma região semiárida tem sido caracterizada, desde o início de sua história, pelo estigma da seca, decorrência da interação entre o meio físico e as estruturas socioeconômicas nele instaladas. O estado do Ceará tem uma área de $148.830 \mathrm{~km}^{2}$, estando $93 \%$ em região do semiárido. De acordo com o relatório do Programa de Ação Estadual de Combate à Desertificação do Estado do Ceará - PAE/CE (2010), as áreas consideradas mais suscetíveis à desertificação são: os sertões dos Inhamuns, os sertões de Irauçuba e Centro-Norte e os sertões do médio Jaguaribe.

Segundo Lemos (2001), os municípios cearenses experimentam grandes obstáculos associados a uma complexa sinergia de fatores que concorrem para a depredação da base de seus recursos naturais que dificultam, ou até inviabilizam, principalmente a produção de bens agrícolas.

Entre esses está o elevado nível de concentração fundiária, que se constitui num reflexo da forma como a terra está apropriada no Brasil, que é uma das mais desiguais do mundo. Isso induz a uma grande concentração de famílias, quase sempre numerosas, em pequenos estabelecimentos ou minifúndios que conduzem a uma superexploração, o que representa uma sobrecarga sobre a base de recursos naturais (IPECE, 2007).

Já nos grandes estabelecimentos, observa-se a substituição do revestimento natural por extensas áreas com pastagens, naturais e/ou plantadas, ou por imensas áreas de monoculturas que têm um impacto marcante sobre a paisagem natural, com efeitos sobre a flora e a fauna nativas (IPECE, 2007).

Outro fator que contribui para essa pressão sobre a base de recursos naturais é a instabilidade climática, cuja melhor tradução é a ocorrência sistemática das secas. Embora o estado do Ceará apresente um nível de precipitação de chuvas relativamente reduzido, isso não constitui o problema crucial, haja vista que se sabe da existência de tecnologias adequadas para a produção agropecuária em condições 
de deficiência hídrica (LUEBS, 1983; VAN BAVEL; HANKS, 1983 apud LEMOS, 2001). Dessa forma, parece que o maior problema referente à ocorrência de precipitação no Estado refere-se à forma irregular com que as chuvas se distribuem, tanto temporal como espacial.

Há ainda a forma como as atividades agrícolas são praticadas na região, que, em muitos casos, provocam um estado de devastação no local. Que de um lado, observam-se as práticas dos pequenos produtores explorando a terra intensivamente, até a exaustão da sua fertilidade natural e sem qualquer prática de reposição dessa fertilidade. Esse tipo de exploração ocorre devido ao extremo nível de pobreza em que vivem as famílias aí localizadas (LEMOS, 2001).

O Governo do Brasil, na qualidade de signatário da referida Convenção, firmou o compromisso de elaborar programas estaduais de combate à desertificação. O relatório do Programa de Ação Estadual de Combate à Desertificação do Estado do Ceará - PAE/CE (2010) classifica como áreas susceptíveis à desertificação, as que possuem as seguintes características: degradação da cobertura vegetal, assoreamento dos rios, pastoreio excessivo, perda da biodiversidade, perda da capacidade de produtividade do solo, baixa relação entre a capacidade produtiva dos recursos naturais e a sua capacidade de recuperação.

Assim, diante de um cenário em que o meio rural apresenta-se fragmentado por múltiplas ações ambientais e antrópicas: meio ambiente frágil, fundamentado em grande parte sobre um embasamento cristalino, com solos rasos, com amplas zonas tropicais semiáridas e uma forte pressão demográfica, que ao longo dos anos tem acontecido desordenadamente, caracterizada pela crescente tensão social, expressa em muitos casos sob a forma de invasões de terras, saques e protestos. Conforme Sarris (2001), essa é a zona em que se concentra a maior parte dos pobres do mundo, com uma renda de menos de um dólar por dia, os quais dependem em grande medida da agricultura. Esse cenário exige estratégias de mitigação das vulnerabilidades climáticas e socioeconômicas às quais estão expostos esses atores sociais que vivem nesse meio.

Dessa forma, há a necessidade do conhecimento da extensão desse problema no estado do Ceará. Assim, o presente estudo objetivou elaborar um índice de propensão à desertificação (IPD) para municípios do Ceará com base em técnicas de análise multivariada e em geoprocessamento no sentido de despertar a atenção dos órgãos governamentais e da comunidade local. 


\section{Referencial teórico}

A conscientização sobre o fenômeno da desertificação começou a difundir-se no mundo logo após uma prolongada seca de seis anos (1968-1973), ocorrida no no Sahel, área que se estende por diversos países africanos. Desde então, governos e pesquisadores estudam um problema que afeta não somente os países localizados na região tropical, mas, também, aqueles situados nas faixas subtropical e temperada (RODRIGUES, 1996, apud RODRIGUES; VIANA, 2014).

Tendo conhecimento dos grandes prejuízos causados, tanto sociais como ambientais e econômicos pela grande seca do Sahel, a Organização das Nações Unidas (ONU) convocou, em agosto de 1977, na cidade de Nairóbi, uma Conferência para ampliar o conhecimento sobre a desertificação, suas consequências socioeconômicas e ambientais e o desenvolvimento e a adoção de medidas de controle nos países atingidos pelo fenômeno (RODRIGUES; VIANA, 2014).

O processo de desertificação é definido e explicado por vários pesquisadores como uma ação predatória do homem sobre ecossistemas a curto e médio prazo (REIS, 1988), um fenômeno integrador de processos econômicos, sociais, naturais e/ou induzidos, que destroem o equilíbrio do solo, da vegetação e da água, bem como, a qualidade da vida humana, nas áreas sujeitas a uma natureza edáfica e/ou climática (FERREIRA et al., 1994).

A desertificação é a degradação do solo em áreas áridas, semiáridas e subúmidas secas, resultante de diversos fatores, inclusive de variações climáticas e, principalmente, de atividades humanas que têm sua origem nas complexas interações de fatores físicos, biológicos, políticos, sociais, culturais e econômicos (ONU, 1992).

Segundo Verdum et al. (2014), duas formulações devem ser consideradas quanto às bases conceituais do processo de desertificação: a evolução bioclimática que tende a transformar uma região em deserto; e as intervenções da sociedade que aceleram a substituição de uma paisagem vegetal em outra abiótica com uma geodinâmica nova. No entanto, não há consenso em relação a essas formulações, tanto no que se refere à influência dos processos naturais como no que diz respeito às possíveis intervenções humanas capazes de induzirem uma transformação ambiental.

Portanto, o estudo da desertificação deve inserir a questão da escala (temporal e espacial), em que são considerados os critérios do ponto de vista climático, social, botânico, pedológico, entre outros. $\mathrm{Na}$ escala temporal, existem formulações tais como o autor define o processo de desertificação; em que período histórico da civilização humana está enquadrado nesse processo e qual a variabilidade do 
conceito de desertificação no tempo. Na escala espacial, existem formulações sobre a localização específica do processo (lugar, área, zona e região), associadas, ou não, a classificações climáticas (VERDUM et al, 2014).

Segundo a Conferência de 1977 no Quênia, os ambientes desérticos são aqueles que apresentam uma diminuição ou uma destruição do potencial biológico da terra. Entende-se, a partir dessa conceituação, que o processo é irreversível, a classificação, nesse caso, ocorre em uma escala de tempo. Em relação à escala espacial observa-se que a desertificação é cartografada em zonas climáticas: áridas, semiáridas e subúmida secas, e, nesse processo, o homem é considerado como um agente de degradação.

De acordo com Le Houerou (1977) apud Verdum et al. (2014), o processo de desertificação está associado à degradação de vários tipos de vegetação e sofre a interferência da variabilidade pluviométrica. Estabelece-se a mesma escala temporal da existência do processo que aquela da conferência do Quênia, contudo, define-se um diferencial quanto à escala espacial que pode ocorrer tanto nas margens dos desertos como em florestas úmidas.

Conforme Goudie (1990) apud Verdum et al. (2014), o processo de desertificação é uma alteração na biomassa com deterioração acelerada do solo, e as atividades humanas e o fator climático são responsabilizados como principais agentes de modificação. O excesso de monocultura, o superpastoreio, a salinização e o desmatamento são possíveis causas da ocorrência do processo de desertificação.

\section{Metodologia}

\section{1 Área de estudo}

Com base no índice de propensão à desertificação calculado pelo Instituto de Pesquisa e Estratégia Econômica do Ceará (Ipece, 2009), foram selecionados, no presente estudo, 10 municípios próximos, considerados como de alto risco de desertificação no Ceará, sendo esses: Alto Santo, Itaiçaba, Jaguaruana, Limoeiro do Norte, Morada Nova, Palhano, Quixeré, Russas, São João do Jaguaribe e Tabuleiro do Norte. Para o índice utilizou-se um estudo de variáveis referentes a fatores naturais e antrópicos, sem o uso de análise multivariada para todos os municípios do Ceará. 


\subsection{Variáveis de estudo}

As variáveis propostas para compor o índice de propensão à desertificação se dividiram em dois grupos: fatores antrópicos e fatores naturais.

\section{a) fatores antrópicos}

I. percentual (\%) de área cultivada/área de estabelecimentos agropecuários: percentual da área cultivada no município em relação ao total da área dos estabelecimentos rurais;

II. valor da produção das lavouras/ ha (2009): valor da produção agrícola dividida pela estimativa de área colhida;

III. valor da produção agrícola / população total (2009): valor da produção agrícola dividida pela população total estimada do município.

IV. carvão vegetal (ton.) (2009): produção de carvão vegetal do município;

V. lenha + madeira em tora $\left(\mathrm{m}^{3}\right)(2008)$ : soma da produção de lenha e madeira em tora do município;.

VI. número de focos de incêndios: número de focos de incêndios;

VII. rebanho de ovinos e caprinos $/ \mathrm{km}^{2}$ (2008): relação entre a soma dos rebanhos de ovinos, caprinos e a área do município em $\mathrm{km}^{2}$;

VIII. rebanho bovino/ $\mathrm{km}^{2}$ (2008): relação entre o rebanho bovino e a área do município em $\mathrm{km}^{2}$;

IX. número de bolsas família/família cadastradas: percentual de famílias que receberam bolsa família com relação ao total de famílias inscritas no cadastro único;

X. anos de escolarização (2000): número de anos de estudo médio da população;

XI. percentual $(\%)$ de terras degradadas e inaproveitáveis em relação à área dos estabelecimentos agropecuários (2006);

XII. percentual (\%) de estabelecimentos agropecuários (unidades) menores que 10 hectares (2006): percentual dos estabelecimentos agropecuários com menos de 10 hectares em relação ao total de estabelecimentos agropecuários;

XIII. percentual (\%) de área com matas e florestas em relação à área dos estabelecimentos agropecuários (2006): percentual da área do município com matas e florestas em relação à área total dos estabelecimentos agropecuários;

XIV. densidade da população rural;

$\mathrm{XV}$. percentual (\%) de área de pastagens degradadas;

XVI. número de tratores existentes nos municípios. 


\section{b) Fatores naturais}

I. percentual (\%) de perda de safra (2009): média percentual das perdas verificadas na produção de grãos no município;

II. índice de distribuição de chuvas (2009): associa as variações volumétricas, temporais e espaciais de chuva, levando-se em consideração o período escolhido para análise;

III. desvio normalizado jan./jun. (2009): variação percentual entre a precipitação observada e a normal (média de 30 anos), na sede do município no período analisado;

IV. índice de aridez (2009): é a precipitação histórica de um determinado ponto dividido pela evapotranspiração potencial (máximo de evaporação que se pode ter em um determinado ponto). Valores acima de um ocorrem para precipitação histórica superior à evapotranspiração potencial, indicando menor grau de aridez. Assim, quanto menor o índice, mais árida é a região;

V. climatologia (2009): medida pela média de precipitação pluviométrica na sede do município nos últimos 30 anos;

VI. qualidade da água: a salinidade mede o teor de sais dissolvidos na água sob a forma de íons e é um dos principais critérios físico-químicos que definem a potabilidade da água. Segundo estabelecido pela organização mundial de saúde (OMS), a água para consumo humano deve ter um teor abaixo de $500 \mathrm{mg} / \mathrm{l}$.

\subsection{Cálculo do índice de propensão à desertificação para os municípios do Ceará}

Para o cálculo do índice de propensão à desertificação (IPD) foi utilizada a metodologia de padronização de indicadores, adotado pelo Instituto de Pesquisa e Estratégia Econômico do Ceará (Ipece) para o cálculo do índice municipal de alerta - IMA (Ipece, 2009b), a qual considera valores de zero a um, indicando menor e maior propensão à desertificação.

$\mathrm{O}$ cálculo do Índice Normalizado para os indicadores considerou a seguinte fórmula:

$$
\mathrm{A}_{1 \mathrm{p}}=\left[\mathrm{A}_{1 \mathrm{i}}-\mathrm{A}_{1 \mathrm{~min}}\right] /\left[\mathrm{A}_{1 \max }-\mathrm{A}_{1 \mathrm{~min}}\right]
$$


Em que:

$\mathrm{A}_{1 \mathrm{p}}$ é o valor padronizado da variável um no município i.

$\mathrm{A}_{1 \max }$ é o maior valor de $\mathrm{A}_{1}$ verificado para o ano do cálculo.

$\mathrm{A}_{1 \min }$ é o menor valor de $\mathrm{A}_{1}$ verificado para o ano do cálculo.

Nos casos em que há uma relação direta de propensão à desertificação, ou seja, o menor valor indica menor propensão à desertificação e o maior valor maior propensão à desertificação, tem-se: $\mathrm{I}_{-\mathrm{V}}=\mathrm{I}_{\min }$ e $\mathrm{I}_{+\mathrm{V}}=\mathrm{I}_{\max }$.

Nos casos de relação inversa com a propensão à desertificação, em que o menor valor indica maior propensão à desertificação e vice-versa, tem-se $I_{+v}=I_{\min }$ e $\mathrm{I}_{\mathrm{V}}=\mathrm{I}_{\text {max }}$.

Após a padronização, os valores mais próximos de um indicam maior propensão à desertificação e o índice de propensão à desertificação é obtido a partir da média aritmética desses valores (IPECE, 2009b):

$$
I P D_{m}=\frac{\sum_{i=1}^{n} F_{i}}{n}
$$

Em que:

$\mathrm{IPD}_{\mathrm{m}}$ é o índice de desertificação do município i.

$\mathrm{F}_{1}$ é o grupo de variáveis antrópicas do município i.

$\mathrm{F}_{2}$ é o grupo de variáveis naturais do município i.

Após a elaboração do índice, foi realizada uma classificação dos municípios cearenses, especificando três classes de vulnerabilidade, descritas da seguinte forma:

- classe um: alta vulnerabilidade, para o índice com valores inferiores ou igual a 0,35 ;

- classe dois: média vulnerabilidade, para o índice com valor maior que 0,35 e menor ou igual à 0,45 ;

- classe três: baixa vulnerabilidade, para o índice com valor acima de 0,45. 


\subsection{Análise fatorial e de componentes principais (ACP)}

Segundo Reis (1997) apud Freitas; Poerschke (2007), a análise dos componentes principais objetivou descrever os dados contidos num quadro indivíduos-variáveis. Podem-se elencar alguns propósitos da ACP como:

a) fornecer medidas responsáveis para captar as maiores variações entre os resultados, sem que se percam muitas informações ao transformar o conjunto original de variáveis em outro conjunto mais resumido de dimensões equivalentes. Tal transformação ocorre com a menor perda de informação possível, sendo que essa também pode auxiliar a eliminar algumas variáveis originais, no caso de possuírem pouca informação;

b) abordar aspectos como geração, seleção e interpretação das componentes investigadas e, ainda, determinar as variáveis de maior influência na formação de cada componente. Com essa técnica, um grande número de informações sobre indivíduos é transformado em um novo conjunto de variáveis que mantém, ao máximo, a variabilidade original do conjunto;

c) agrupar indivíduos similares mediante inspeções visuais em dispersões gráficas no espaço bi ou tridimensional, o que facilita a interpretação geométrica. Essa redução da dimensionalidade é chamada transformação de Karhunnen-Loéve, ou, ACP, no qual os autovalores encontrados são denominados de componente principal. $\mathrm{O}$ algoritmo se baseia na matriz de variância-covariância, ou na matriz de correlação, da qual são extraídos os autovalores e os autovetores. Em suma, o que o método traduz é a criação de novas variáveis não correlacionadas, obtidas de combinações lineares das variáveis iniciais, as quais são apresentadas em ordem decrescente relativas ao seu poder de explicação - as componentes principais.

O processo tem cinco passos: a) coleta da matriz de dados (Xn); b) determinação da matriz de correlação (R), ou a matriz de variância-covariância amostral (S) dos dados originais (Xn); c) encontrar os autovalores (ÙL) - raízes características; e, por fim, d) chega-se aos autovetores (x) que possibilitam encontrar as novas variáveis/escores $(\mathrm{Yn})$. De pronto, calcula-se a matriz $\mathrm{S}$, ou matriz $\mathrm{R}$, e verifica-se se as variáveis estão correlacionadas uma com as outras. Aplicam-se os testes Kaiser-Meyer-Olkin Measure of Adequacy (KMO) e o teste de esfericidade de Bartlett. O primeiro testa o grau de adequação da base de dados e o segundo a hipótese de a matriz estabelecer correlações e se constituir como uma matriz de identidade.

Conforme Rummel (1967) apud Freitas; Poerschke (2007), a análise fatorial "toma milhares e, potencialmente, milhões de medidas quantitativas e determina 
a ocorrência de padrões distintos entre elas", o que responde à questão de qual é o padrão de conexão que explica a relação entre as variáveis. Então, a análise fatorial objetiva descobrir fatores que expliquem o que existe de comum nas variáveis originais.

Já selecionados os fatores e batizados, esses são submetidos a uma rotação, mantendo a ortogonalidade entre eles. "O objetivo da rotação ortogonal consiste em transformar os fatores obtidos em novos fatores independentes" (FREITAS; POERSCHKE, 2007). A rotação altera a parcela de contribuição de cada fator, mas mantém os valores das comunalidades e a proporção de variância explicada pelo conjunto de fatores, pois, ela maximiza a carga de uma variável em um único fator, permitindo que, assim, melhor se represente cada um deles.

A rotação varimax foi o método escolhido para rotacionar os eixos por ser um método bastante utilizado e difundido na literatura consultada. Esse "forma um novo sistema de eixos ortogonais com o mesmo número de fatores e permite que o grupo de variáveis apareça com maior nitidez", facilitando a interpretação e a análise (ZAMBRANO; LIMA, 2004 apud FREITAS; POERSCHKE, 2007). O método maximiza a soma das variâncias das cargas fatoriais e busca a simplificação das colunas da matriz fatorial. A simplificação máxima é conseguida se houver apenas cargas fatoriais próximas de um ou zero. Quando as correlações são próximas de +1 ou -1 indicam clara associação positiva ou negativa e, quando próximas de zero, indicam a falta de associação entre fator e variável.

E, por fim, foram calculados os escores fatoriais para cada observação. O escore fatorial ou o índice foi obtido pela multiplicação do valor padronizado da variável $\mathrm{n}$ pelo coeficiente do escore fatorial correspondente. Esses valores constituem, exatamente, as projeções normalizadas dos pontos representativos das unidades sobre os eixos dos fatores que, por construção, tem média zero e desvio-padrão unitário. Dessa forma, Freitas; Poerschke (2005) salientam que elevados escores fatoriais positivos ou negativos mostrarão que tal observação tem alta influência daquele fator.

\subsection{Análise espacial da área propensa a desertificação em ambiente SIG}

A seleção de indicadores considerou o resultado apresentado pela análise multivariada de componentes principais. Foram analisados inicialmente 22 indicadores, priorizando aqueles que apresentavam maior potencialidade para fornecer informações sobre os processos de degradação ambiental e de desertificação, sem 
deixar de considerar a questão do acesso aos dados. Dos 22 indicadores analisados por meio da análise fatorial, apenas nove foram selecionados.

Em uma segunda etapa, em ambiente de Sistema de Informação Geográfico, (SIG) foram adicionados mais cinco indicadores para compor o índice de Propensão à Desertificação: o uso do solo, a intensidade de precipitação, o número de veranicos com dez dias sem chuvas, a perda de solo e a geologia.

Um Sistema de Informação Geográfico é um sistema de hardware, software, informação espacial e procedimentos computacionais que permite e facilita a análise, gestão ou representação do espaço e dos fenômenos que nele ocorrem. Envolve um sistema constituído por um conjunto de programas computacionais, o qual integra dados, equipamentos e pessoas com objetivo de coletar, armazenar, recuperar, manipular, visualizar e analisar dados especialmente referenciados a um sistema de coordenadas conhecido.

Foram feitas a avaliação e a validação da qualidade da base de dados, ou seja, todos os dados foram checados, visando assegurar a sua qualidade antes do início do geoprocessamento. Depois da checagem, foi elaborada uma listagem com a caracterização geral de todos os dados a serem empregados (KAZMIERCZAK, 1998).

Para manipulação do Índice de Propensão a Desertificação (IPD) foi gerada uma grade com resolução de $30 \mathrm{~m}$. Assim, cada elemento da grade considera uma área de $30 \mathrm{mx} 30 \mathrm{~m}$, de forma a incorporar os valores atribuídos para cada um dos indicadores considerados na célula em questão. Os valores de cada polígono (classe) de cada indicador foram transferidos para essa grade, de forma a dispor todos os valores de todos os indicadores em um único arquivo. Para isso, foram feitas operações de análise espacial selecionando-se as células da grade que interceptavam os polígonos de cada indicador.

O método básico de estimativa utilizado foi o da krigagem que se trata de um processo de estimação por médias móveis, de valores de variáveis distribuídas no espaço, a partir de valores adjacentes, considerados como interdependentes por uma função denominada variograma (KAZMIERCZAK, 1998).

A krigagem usa informações, com base no variograma para encontrar os pesos ótimos a serem associados às amostras com valores conhecidos que irão estimar pontos desconhecidos. Nessa situação, o método fornece, além dos valores estimados, o erro associado a tal estimação, o que o distingue dos demais algoritmos de interpolação. É entendida como uma série de técnicas de análise de regressão que procura minimizar a variância estimada, com base em um modelo prévio, que leva em conta a dependência estocástica entre os dados distribuídos no espaço. Dentre os métodos de estimativas, comumente empregados, o método geoestatístico da 
krigagem pode ser considerado como o melhor estimador linear sem viés, cujo objetivo é a minimização da variância da estimativa (KAZMIERCZAK, 1998).

\section{Resultados e discussão}

\subsection{Indicadores de propensão à desertificação no Ceará}

Das vinte e duas variáveis iniciais analisadas, treze foram eliminadas, tendo por base os preceitos apresentados por Freitas e Poerschke (2007) de que a normalidade multivariada, a multicolinearidade e linearidade impactam na análise fatorial interferindo na observação das correlações entre as variáveis.

Para identificar as variáveis de maior significância na explicabilidade da variância total dos dados originais, elaborou-se um teste de sensibilidade, no qual permaneceram somente aquelas que apresentaram correlações superiores a 0,30 ; teste de KMO superior a 0,50; Measure of Sampling Adequacy (MSA) superior a 0,50; Bartlett test of Shericity com significância menor que 0,05.

$\mathrm{Na}$ Tabela 1, quanto à análise das comunalidades, em quase sua totalidade, as variáveis utilizadas no modelo apresentaram uma explicabilidade alta, pois a maioria das comunalidades e das MSA foram superiores a 0,60 , considerando todos os fatores obtidos.

Tabela 1 - Comunalidades e medida de adequabilidade da amostra (MSA) das variáveis encontradas pelo modelo de análise fatorial

\begin{tabular}{l|c|c}
\hline \multicolumn{1}{c|}{ Variáveis } & Comunalidades & MSA \\
\hline \% Área cultivada/Área de estabelecimento agropecuário (2009) & 0,58 & 0,82 \\
Lenha + madeira em tora $\left(\mathrm{m}^{3}\right)(2008)$ & 0,80 & 0,61 \\
Rebanho de ovinos e caprinos/ $\mathrm{km}^{2}(2008)$ & 0,56 & 0,76 \\
Índice de distribuição de chuvas (2009) & 0,77 & 0,77 \\
Índice de aridez (2009) & 0,66 & 0,76 \\
Climatologia (2009) & 0,80 & 0,73 \\
Qualidade da água (Condutividade Elétrica) & 0,65 & 0,53 \\
Área de pastagens degradadas & 0,64 & 0,64 \\
\% de estabelecimentos agropecuários (unidades) < 10 hectares (2006) & 0,62 & 0,79 \\
\hline
\end{tabular}

Fonte: Dados da Pesquisa (2013).

A Tabela 2 permite identificar a extração de três fatores do modelo com raízes características (autovalores) maiores do que um (MENDES, 2005), os quais explicaram cerca de $67,76 \%$ da variância dos dados analisados. O modelo obteve um KMO igual a 0,75 e um Teste de Bartlett igual a 614,37, expressando um bom nível de significância. 
Tabela 2 - Cargas fatoriais após a rotação ortogonal

\begin{tabular}{l|c|c|c}
\hline \multicolumn{1}{c}{ Variáveis } & \multicolumn{3}{c}{ Componentes } \\
\cline { 2 - 4 } & 1 & 2 & 3 \\
\hline \% Área cultivada/Área de estabelecimento agropecuário (2009) & $-0,75$ & $-0,06$ & $-0,13$ \\
Lenha + madeira em tora $\left(\mathrm{m}^{3}\right)(2008)$ & 0,03 & 0,07 & 0,89 \\
Rebanho de ovinos e caprinos/km² (2008) & 0,33 & $-0,30$ & 0,60 \\
Índice de distribuição de chuvas (2009) & 0,85 & 0,20 & 0,04 \\
Índice de aridez (2009) & 0,79 & $-0,11$ & 0,18 \\
Climatologia (2009) & 0,89 & $-0,02$ & 0,10 \\
Qualidade da água (Condutividade Elétrica) & 0,15 & $-0,79$ & $-0,04$ \\
Área de pastagens degradadas & 0,34 & 0,70 & $-0,19$ \\
\% de estabelecimentos agropecuários (unidades) <10 hectares (2006) & $-0,65$ & 0,45 & 0,02 \\
Autovalor & 3,37 & 1,48 & 1,25 \\
\% da Variância & 37,41 & 16,43 & 13,92 \\
Variância acumulada \% & 37,41 & 53,84 & 67,76 \\
\hline
\end{tabular}

Fonte: Dados da Pesquisa (2013).

Após a geração da matriz de componentes principais rotacionada, verificou-se a seguinte composição dos três fatores encontrados:

- fator um (Agricultura e Climáticos): percentual de área cultivada (\%) / área dos estabelecimentos agropecuários, percentual de estabelecimentos agropecuários (unidades) menores que 10 hectares (\%), índice de distribuição de chuvas, índice de aridez e climatologia;

- fator dois (Qualidade da Água e Pastagens): qualidade da água (condutividade elétrica) e área de pastagens degradadas;

- fator três (Extrativa Vegetal e Pecuário): Lenha + madeira em Tora $\left(\mathrm{m}^{3}\right)$ e Rebanho de ovinos e caprinos $/ \mathrm{km}^{2}$.

Após feita a composição dos fatores, foi possível identificar que o primeiro fator "Agricultura e Climáticos" explica 37,41\% da variância total dos dados. Esse fator mostrou a instabilidade climática, representada pela ocorrência sistemática de secas, em que o maior problema refere-se à forma irregular da distribuição das chuvas, tanto de forma temporal como de forma espacial.

Já quanto à exploração da terra, referente às atividades agropecuárias, essas apresentaram um quadro cearense em que cerca de $90 \%$ de suas terras agrícolas são cultivadas por pequenos produtores rurais que exploram a terra intensivamente até a exaustão de sua fertilidade natural, sem qualquer prática de reposição da 
fertilidade perdida. Esse tipo de exploração ocorre devido ao nível de pobreza em que vivem as famílias, sendo a principal preocupação dessas pessoas, a sobrevivência (IPECE, 2007), estando, portanto, intrinsecamente correlacionada com o processo de desertificação.

O segundo fator, qualidade da água e pastagens, explica 16,43\% da variância total, indicando que o elevado nível de sais presentes na água dos poços dos municípios cearenses é um fator significativo quanto à propensão à desertificação, pois, a salinização primária consiste na acumulação de sais por processos naturais, devido a um elevado teor de sais nos materiais de origem ou nas águas subterrâneas.

O terceiro fator fundiário e pecuário explica $13,92 \%$ da variância total, expressando a questão da pressão que a pecuária exerce sobre as matas nativas juntamente com a extração de madeira pela população rural para a produção de lenha e carvão. Esse fator envolve a eliminação da cobertura vegetal natural, causada tanto pelos sistemas de exploração agrícolas como pelo fato dessa vegetação ainda ser utilizada como a principal fonte de energia pelos pequenos estabelecimentos rurais sob a forma de lenha.

Esses três fatores explicam conjuntamente mais de $67 \%$ da variância total dos dados, expressando que o resultado dessa complexa interação de fatores entre o homem e o ecossistema gera a degradação dos recursos naturais e das condições de sobrevivência das famílias que dependem do meio rural e da produção agropecuária para sua subsistência.

De acordo com Mendes (2005), na análise fatorial as variáveis são agrupadas em função de suas correlações, isso significa que as variáveis que compõem um determinado fator devem estar altamente correlacionadas entre si e fracamente correlacionadas às variáveis que entram na composição de outros fatores.

Logo, neste estudo, a decomposição dos fatores expressa que a propensão à desertificação nos municípios cearenses está relacionada com as condições climáticas existentes, com o desenvolvimento e com o teor de sais presentes na água e consequentemente no solo.

\subsection{Identificação da área propensa à desertificação em ambiente SIG}

Partindo dos resultados apresentados pela análise multivariada, foram agregados mais cinco indicadores tais como, o uso do solo, a intensidade de precipitação, o número de veranicos com 10 dias sem chuvas, a perda de solo e a geologia, todos trabalhados em ambiente de sistema de informação geográfico (SIG) para o 
cálculo do índice de propensão à desertificação (IPD). Todos os indicadores foram trabalhados por meio de técnicas geoestatísticas e de álgebra de mapas.

Analisando a Figura 1, verificou-se que os municípios da amostra estão localizados em uma região de média propensão à desertificação.

Figura 1 - Índice de propensão à desertificação dos municípios analisados no Ceará

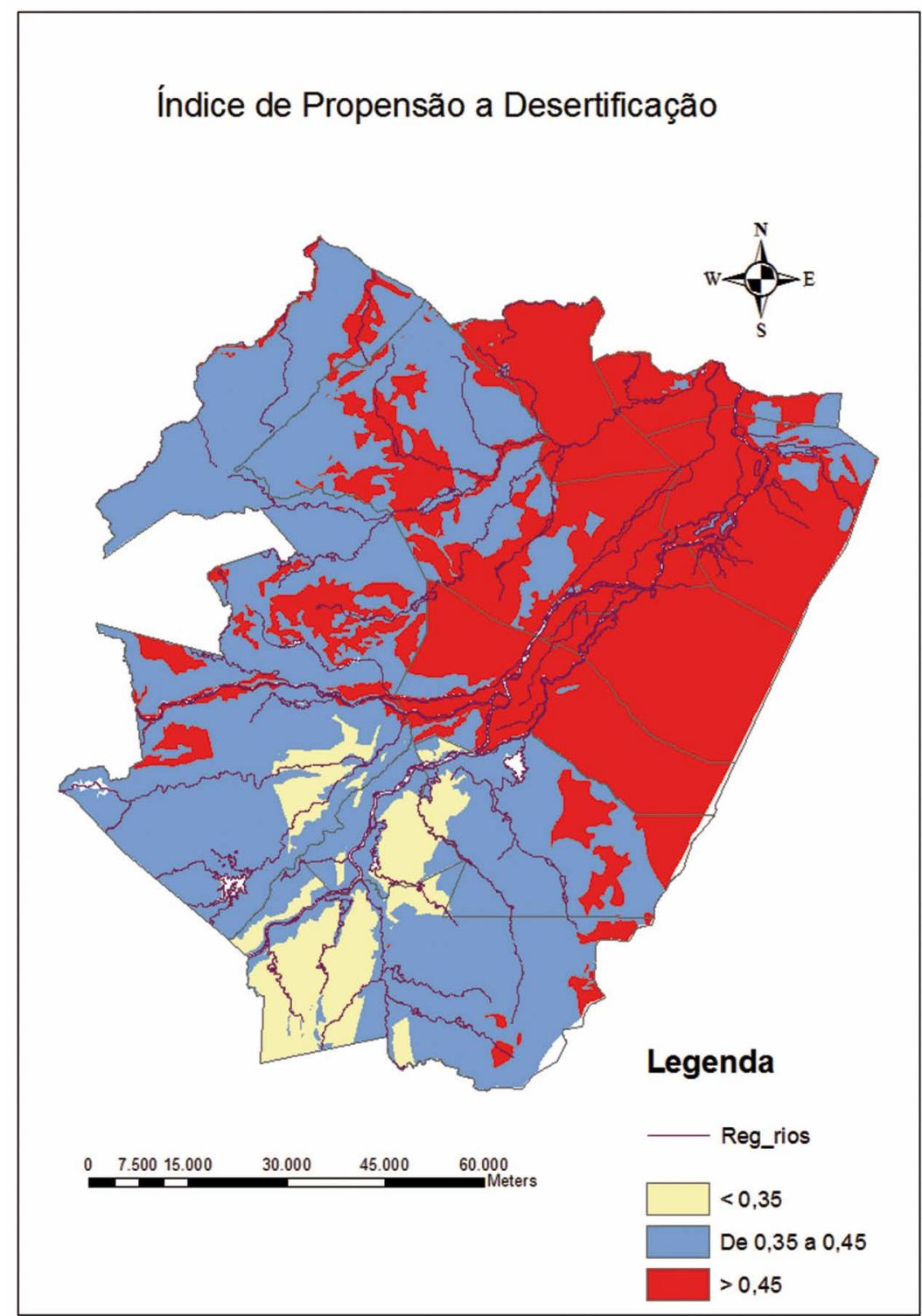

Fonte: Elaborado pelos autores (2013). 
Verificou-se, conforme o cálculo do índice de propensão à desertificação, que cerca de $42 \%$ da área total dos municípios analisados encontram-se localizadas em área de baixa propensão à desertificação, ou seja, baixa vulnerabilidade (índice com valor acima de 0,45); $51 \%$ em área de média propensão (média vulnerabilidade para índice com valor maior que 0,35 e menor ou igual a 0,45) e 7\% em área de alta propensão à desertificação, ou seja, alta vulnerabilidade (índice com valores inferiores ou igual a 0,35 ).

Dos municípios analisados, Quixeré, Limoeiro do Norte, Jaguaruana, Palhano e Itaiçaba são os que estão em pior situação quanto à propensão à desertificação. Dentre os indicadores que contribuíram para o índice mais elevado de propensão à desertificação,tem-se: tipo de solo, qualidade da água dos poços (condutividade elétrica), geologia, número de estabelecimentos agrícolas menores do que 10 hectares, percentual de área cultivada no município e intensidade pluviométrica.

Verifica-se, então, que Rodrigues e Viana (2014) encontraram resultados semelhantes em pesquisa no Ceará que apresentou níveis preocupantes de degradação ambiental em diversos e variados municípios.

\section{Conclusão}

Embora o processo de desertificação já tenha sido tratado por muitos pesquisadores, observa-se que não houve evolução da aplicação efetiva das leis e soluções técnicas propostas pelas entidades públicas ou privadas, as quais defendem, prioritariamente, a implementação de medidas preventivas para as terras ainda não atingidas pela desertificação ou que estão apenas levemente degradadas.

Verificou-se que os indicadores que mais influenciaram os resultados quanto à propensão à desertificação foram os fatores climáticos e os fatores antrópicos causados pelo homem, tais como a expansão da fronteira agrícola, a superexploração dos minifúndios e o aumento do rebanho de ovinos e caprinos, os quais provocam um aumento da compactação do solo pela forte pressão sobre o pasto existente, que vai ao longo dos anos provocando a degradação dessas áreas e, consequentemente, a desertificação.

O aprofundamento de estudos e a busca de soluções seriam formas de reverter o processo de desertificação. Uma alternativa seria a análise do processo de forma sistêmica ou holística, não apenas nos seus aspectos antrópicos e naturais, mas também por meio das dinâmicas da distribuição da riqueza e da renda geradas pelas atividades econômicas e por pressões demográficas. 


\title{
Index of propensity to desertification in the state of Ceará
}

\begin{abstract}
The present study aimed to develop an index of propensity to desertification (IPD) for municipalities in the state of Ceará based on multivariate analysis techniques. The data were collected secondary nature of the Institute for Research and Economic Strategy of Ceará (IPECE, 2009) addressing variables pertaining to natural and man-made factors. Were selected ten neighboring municipalities and high-risk desertification in Ceará. The results showed that the most influential indicators as the propensity to desertification were the climatic factors and man-made factors caused by man, such as expansion of the agricultural frontier, over-exploitation of small plantations and the increase in the herd of sheep and goats, which cause an increase in soil compaction by strong pressure on the pasture, which goes over the years causing desertification.
\end{abstract}

Keywords: Natural and man-made factors. Factor analysis. Ceará.

\section{Índice de propensión a la desertificación en el estado de Ceará}

\section{Resumen}

El presente estudio pretende desarrollar un índice de propensión a la desertificación (IPD) para los municipios en el estado de Ceará basada en técnicas de análisis multivariado. Los datos fueron recogida naturaleza secundaria del Instituto de Investigación y Estrategia Económica de Ceará (IPECE, 2009) abordar las variables relativas a factores naturales y antropógenos. Los 10 vecinos municipios fueron seleccionada y de alto riesgo contra la desertificación en Ceará. Los resultados mostraron que los indicadores más influyentes como la propensión a la desertificación eran los factores climáticos y factores antropógenos causaron por el hombre, como la expansión de la frontera agrícola, la explotación excesiva de las pequeñas plantaciones y el aumento en el rebaño de ovejas y cabras, que provocan un aumento en la compactación del suelo por la fuerte presión sobre el pasto existente, que recorre los años provocando la desertificación.

Palabras clave: Factores naturales y antropógenos. Análisis factorial. Ceará. 


\section{Referências}

CEARÁ. Secretaria dos Recursos Hídricos. Programa de Ação Estadual de Combate à Desertificação e Mitigação dos Efeitos da Seca, PAE-CE, Fortaleza: Ministério do Meio Ambiente / Secretaria dos Recursos Hídricas, 2010.

FERREIRA, D. G. et al. A desertificação no Nordeste do Brasil: diagnóstico e perspectiva. Teresina: UFPI, 1994.

FREITAS, Clailton Ataíde; POERSCHKE, Rafael Penteado. Um retrato da modernização agropecuária nos coredes agrícolas do Rio Grande do Sul: uma aplicação da análise multivariada. Santa Maria: Universidade Federal de Santa Maria, 2007.

GOUDIE. A. S. Desert degradation. In: Techniques for desert reclamation. Chichester: Wiley, 1990. 286p.

Instituto de pesquisa e Estratégia Econômica do Ceará - IPECE. Índice Municipal de Alerta IMA 2007. Fortaleza: Ipece, 2007.

Instituto de pesquisa e Estratégia Econômica do Ceará - IPECE. Proposta de índice de desertificação para o estado do Ceará. Fortaleza: IPECE, 2009a. 18p. (Nota Técnica N. 41).

IPECE, Instituto de pesquisa e Estratégia Econômica do Ceará. Índice Municipal de Alerta IMA 2009. Fortaleza: Ipece, 2009b.

KAZMIERCZAK, M. L. Desenvolvimento de um algoritmo para modelar a susceptibilidade de desertificação no Nordeste do Brasil: algoritmo ISD. SIMPÓSIO BRASILEIRO DE SENSORIAMENTO REMOTO, IX. Santos, Brasil, 11-18 setembro 1998, INPE. Anais...

LE HOUEROU, H. N. A natureza e as causas da desertificação. In: Reunião IGU sobre Desertificação. Cambridge: Westview Press, 1977.

LEMOS, José de Jesus Sousa. Níveis de degradação no Nordeste brasileiro. Revista Econômica do Nordeste, Fortaleza, v. 32, n. 3 p. 406-429, jul.-set. 2001.

MENDES, Lúcia Maria Silveira. Construção e interpretação de uma base nacional de dados edafoclimáticos e sua relação com dados socioeconômicos. 250p. Tese (Doutorado em Agronomia)

- Escola Superior de Agricultura Luiz de Queiroz, Piracicaba, 2005.

ONU. Agenda 21. Manejo de ecossistemas frágeis: a luta contra a desertificação e a seca. In: CNUMAD: Conferência das Nações Unidas sobre o Meio-Ambiente e Desenvolvimento. Rio de Janeiro, 1992.

REIS, J. G. Desertificação no Nordeste. Recife: Sudene, 1988.

RODRIGUES, M. I. V. Desertificação e construção de um coeficiente interdisciplinar para o estado do Ceará. Fortaleza: Faculdade de Economia/UFC, 1996. Monografia (Graduação em Ciências Econômicas).

RODRIGUES, M. I. V.; VIANA, M. O. de L. Desertificação e construção de um coeficiente interdisciplinar para o estado do Ceará. Disponível em: http://www.ecoeco.org.br/conteudo/publicacoes/ encontros/ii_en/mesa1/4.pdf. Acesso em: 01 jul. 2014.

SARRIS, Alexander H. O papel da agricultura no desenvolvimento econômico e na diminuição da pobreza: uma base empírica e conceitual. Atenas: Universidade de Atenas, 2001.

VERDUM, R.; QUEVEDO, D.; ZANINI, L. S. G.; CÂNDIDO, L. A. Desertificação: questionando as bases conceituais, escalas de análise e consequências. Disponível em: http://www.uff.br/geographia/ojs/index.php/geographia/article/viewArticle/68. Acesso em: 01 jul. 2014. 